\title{
Haematologic profile and prevalence survey of haemonchosis in various breeds of
} slaughtered cattle in Ibadan, Nigeria

"Jeremiah, O. T. and Banwo, O. G.

Department of Veterinary Medicine, University of Ibadan

"Correspondence author: otjeremiah2015@gmail.com (+2348023469574)

\section{Abstract}

This study was aimed at determining the haematological profile and prevalence of Haemonchus parasites in cattle considering the breed, sex, age and body condition scores (BCS) of the animals. The study spanned over 12 months. Whole blood samples were collected from various breeds of cattle with adult Haemonchus specimens from each abomasum content of such animals slaughtered at a local abattoir in Ibadan, southwestern Nigeria. Systematic random sampling method was adopted, with a working sample size of 322. The age and BCS of cattle sampled were estimated using rostral dentition technique and visual indicators, respectively. The adult Haemonchus worms were collected in normal saline and identified morphologically. The haematologic profile was determined using pocH100iV Diff $f^{R}$ (Haematology System, Sysmex Animal Health Germany). Data obtained from this study were analyzed statistically using microsoft excel, SPSS (Version 20), and graphPad prism version 5.0 with Fisher's exact test. Haematological profile in bovine haemonchosis showed anaemia with an overall mean packed cell volume (PCV) of $25.59 \pm 0.03 \%$, whereas the apparently healthy cattle had a mean PCV of $34.52 \pm 0.02 \%$. The overall prevalence of bovine haemonchosis was $16.6 \%$. Our findings revealed that prevalence of bovine haemonchosis varied with months, season, body condition score, age, breeds with no sex predisposition. There is a need for constant monitoring of gastrointestinal parasites, appropriate anthelminthic regimen and control measures to promote animal production and prevent huge economic losses as a result of subclinical, acute illness and death in severe levels of parasitism.

Keywords: cattle, haematology, prevalence, haemonchosis.

\section{Introduction}

Gastrointestinal nematode infections are chronic pervasive infections that contribute worldwide to morbidity and mortality in livestock (Alawa et al., 2011). Due to these parasitic conditions, the productivity of animals is constrained with consequent reduced animal performance and mortality (Soulsby, 1982). Ruminant haemonchosis is a serious health, which causes lower production due to morbidity, mortality, and cost of treatment, and control measures (Radostits et al., 2007). The genus Trichostrongyle represents the most economically important helminth parasites in domesticated ruminants worldwide (Gibbs and Herd, 1986). The genus includes the species Haemonchus contortus
(Rudolphi, 1803 cited by Hoberg et al., 2001), Haemonchus placei (Place, 1893 cited by Riggs, 2001) and Haemonchus similis (Travasso, 1914 cited by Achi et al., 2003), which are globally distributed in ruminants. $H$. placei infects primarily cattle, while $H$. contortus is mainly a parasite of sheep (Radostits et al., 2006). However, both worms are found in other domestic and wild ruminants as well as in other hosts (Kaufmann, 1996). The average values of several morphological traits differ between populations of Haemonchus species from cattle and sheep, but phenotypic distributions often overlap, requiring measurements on multiple characters in order to classify individual 


\section{Haematologic profile and prevalence survey of haemonchosis}

nematodes (Kaufmann, 1996, Knox et al., 2006). The prophylaxis of parasitic gastroenteritis rely heavily on anthelmintic treatments. However, there have been many reports of anthelmintic resistance, including resistance to Haemonchus species, in small ruminants (Saddiqi et al., 2010) and cattle (Knox et al., 2006). Therefore, knowledge regarding the epidemiology of parasitic gastroenteritis, is essential for the establishment of sustainable strategies of parasite control. In northern Nigeria, helminthosis was found to rank the highest among diseases of slaughtered ruminants encountered in an abattoir in Zaria (Alawa et al., 2011). Specifically, in the southwestern part of Nigeria, bovine haemochosis has been found to be an important helminth disease among slaughtered cattle in Ibadan (Adedipe et al., 2014). The same trend has been observed in the southern part of Nigeria (Elele et al., 2013). Breed susceptibility to haemochosis is very essential in the epidemiology of the infection as it relates to ruminant animals (Odoi et al., 2007). However, the use of blood picture and body score technique as part of tools for the survey of bovine haemochosis is limited in literature. Therefore, the present work was aimed at investigating the haematologic profile and the prevalence of haemonchosis in slaughtered cattle of different ages, breeds, sexes and body scores in Ibadan, southwestern Nigeria.

\section{Materials and methods}

\section{Location of study and cattle breeds}

This work was carried out at the Bodija Municipal Abattoir located in Ibadan North Local Government Area of Oyo State, Nigeria. The abattoir is located at latitude $7^{\circ} 20 \mathrm{~N}$ and longitude $3^{\circ} 5 \mathrm{E}$ (Filani et al., 1994). The abattoir is the biggest of all the abattoirs in the State. A total of 322 cattle were sampled and Haemonchus worms were collected from the abomasum content of each animal over a period of 12 months. Cattle breeds encountered during the study included White Fulani (WF, $\mathrm{n}=175$ ), Sokoto Gudali ( $\mathrm{SG}, \mathrm{n}=92$ ), Red Bororo (RB, $n=37)$, Kuri (K, n=18). These cattle being slaughtered at the abattoir originated from smallholder farms around Ibadan, the derived Guinea savannah, sahel and subarid climatic zones of northern Nigeria and border countries such as Niger, Chad and Mali.

\section{Sample collection}

Systematic random sampling method was employed in selecting cattle that were screened at postmortem. For each animal sampled, the breed, sex, age and body condition score were recorded. The age of each animal was estimated using rostral dentition technique as earlier described by Lasisi et al. (2002). The body condition score (BCS) was based on visual assessment during postmortem in which scoring was based on the level of fat deposition and muscle around/over the vertebrate in the loin region and omental fat deposition, on a scale of 1 through 9 as modified by Landblom et al. (2006). The nematode worms were observed visually and recovered using standard techniques in situ as described earlier by Jeremiah and Banwo (2018). Other laboratory procedures were carried out as described by Hansen and Perry (1994). The abomasum of each animal was opened along the side of the greater curvature and its contents were filtered through a sieve with an aperture of about $250 \mu \mathrm{m}$ being capable of retaining the larvae. The abomasal contents were then washed into a bucket with water, and thus 2 liters of the total volume was made. Inside a labelled plastic container, a duplicate of 200 $\mathrm{mL}$ was transferred and $10 \%$ formalin was added as preservative. About $20 \mathrm{~mL}$ of the aliquot was taken onto a Petri dish and about 


\section{Jeremiah and Banwo}

$3 \mathrm{~mL}$ of iodine added for coloration and about $3 \mathrm{~mL}$ of sodium-thiosulphate also added to facilitate easy identification and examination of the worms under light microscope. The total number of parasites found in the abomasum was derived from the product of $20 \mathrm{~mL}$ and 100 (Abebe and Esayas, 2001). The Haemonchus worms were identified up to the genus level based on the characteristics as described by Kaufmann (1996). At the slit jugular vein during slaughtering, whole blood $(5 \mathrm{~mL})$ samples were collected (from the apparently healthy cattle and those that had haemonchus worms) into bijou bottles containing disodium ethylene diamine tetra acetic acid (Na2EDTA) as anticoagulant according to the techniques earlier described by Jeremiah and Folorunso (2019). The packed cell volume (PCV), total erythrocyte and leukocyte counts, and haemoglobin concentration were determined using pocH-100iV Diff (Sysmex Animal health, Germany); the derived values for the haematological parameters were compared with established data (Radostits et al., 2007). Only apparently healthy cattle and those that were not diagnosed with ectoparasites (such as ticks, lice and fleas), haemoparasites (such as trypanosomes, babesia and theileria organisms), tapeworms or liver flukes and coccidiosis were used for the study following clinical and standard laboratory techniques (Soulsby, 1982). Statistically, all data obtained were subjected to descriptive analysis using microsoft excel, SPSS (Version 20), and graphPad prism version 5.0. Group means of qualitative variables were compared using Fisher's exact test at 5\% significance level. The results are presented as means and standard error of means.

\section{Results}

The monthly occurrence of haemonchosis in cattle was studied for a period of one year as shown in Figure 1. The highest prevalence $(40.7 \%)$ was recorded during the month of July, while the lowest $(2.17 \%)$ was recorded in the month of December. However, no incidence of bovine haemonchosis was recorded in the months of January and February. The mean prevalence was found to be $16.6 \%$. The maximum number of cattle sampled coincided with the highest level of occurrence in the month of July, while the lowest number of cattle coincided with the lowest level of occurrence during the month of December (Figure 1). In the course of the sampling, the gross appearance of the haemonchus worms revealed the "woollike" nature of the worms during separation from the abomasal contents (Plate 1). Furthermore, the microscopic view (at X 40 magnification) of the worms revealed their spiral nature (Plate 1). The haematologic profile of all the cattle sampled in this study is represented in Table 1. All the erythrocyte indices of cattle that were positive for haemochosis showed significant $(\mathrm{P}<0.05)$ difference from those that were negative. For instance, the mean packed cell volume (PVC) value for cattle with haemochosis was $25.59 \pm 0.03 \%$ while that for the apparently normal cattle was $34.52 \pm 0.02 \%$. However, there was no significant difference $(\mathrm{P}>0.05)$ in the value of the white blood cell counts of cattle that were positive for haemochosis and those that were negative. In the course of the study, more cows were encountered than bulls and the ratio of male to female animals was 1.67 (Table 2). There was no significant difference in the sex predisposition $(\mathrm{P}=$ $0.2490 ; \mathrm{P}>0.005)$ between male and female animals with haemochosis. The White Fulani breed of cattle ranked the highest among the breeds of cattle sampled while Kuri cattle were the least sampled cattle. Across all the cattle breeds, older animals 


\section{Haematologic profile and prevalence survey of haemonchosis}

were more in number than the younger ones (Table 2). Table 3 represents the breed, age and sex disposition to bovine haemochosis in this study. Animals less than a year $\left(\mathrm{P}_{0}\right)$ were found to be least susceptible with prevalence of $1.2 \% \quad(n=4)$. However, animals around age of three and three and half years $\left(\mathrm{P}_{3}\right)$ appeared to be most susceptible to haemochosis with prevalence of $16.5 \%(n=53)$. It was observed that few young animals were slaughtered at the abattoir. Table 4 shows the relationship of body score of animals with incidence of haemonchosis among the cattle sampled. Only $13.4 \%$ of all the cattle with good body score were found with haemonchosis, while $27.3 \%$ of all the cattle with medium body score were found with haemonchosis.

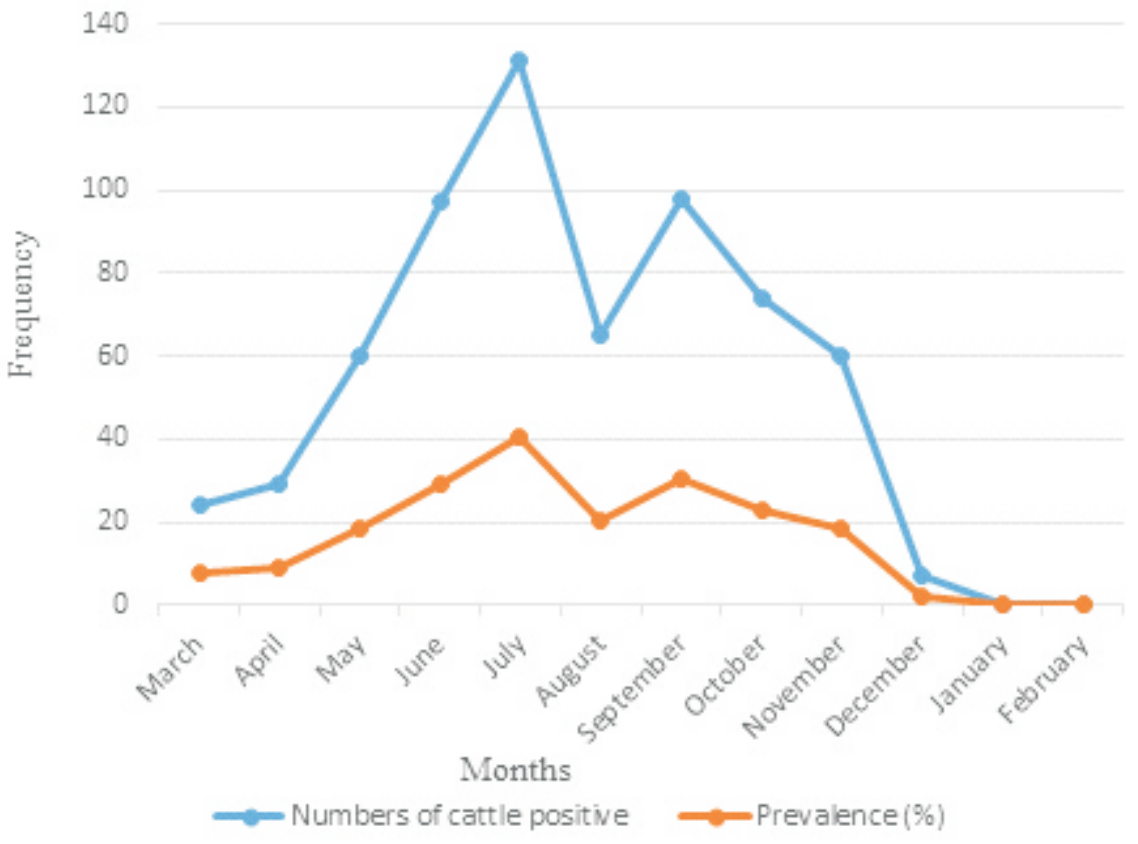

Figure 1: Occurence of Haemonchosis in cattle

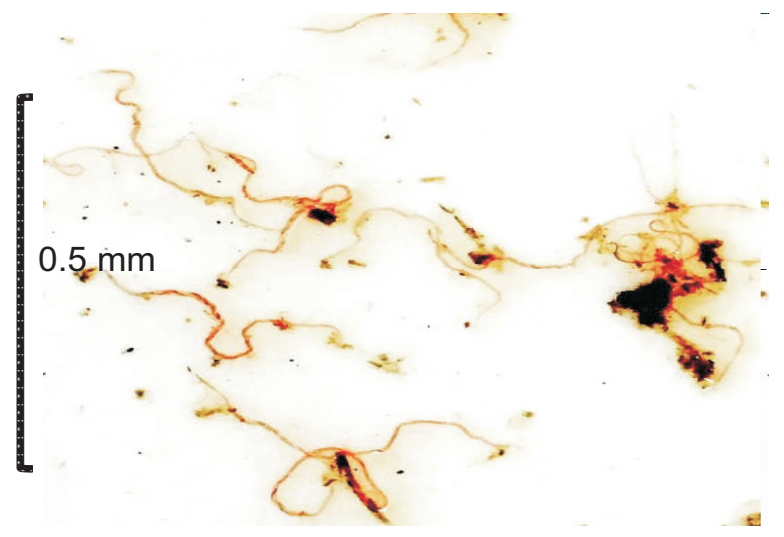

Plate 1: Haemonchus species (Gross) 


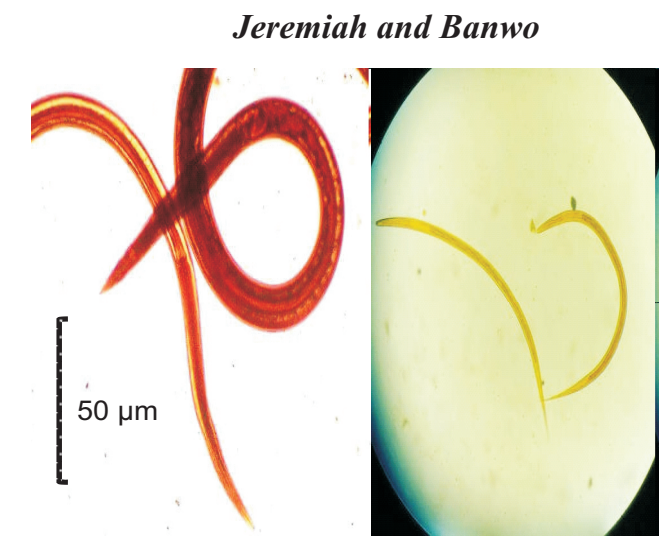

Plate 2: Microscopy of Haemonchus species X40

Table 1: Mean \pm SEM values of haematological parameters in cattle with and without haemonchosis

\begin{tabular}{lccccccc}
\hline \multicolumn{1}{c}{ Parameter } & $\begin{array}{c}\text { PCV } \\
(\mathbf{\%})\end{array}$ & $\begin{array}{c}\text { RBC count } \\
\left(\times \mathbf{1 0}^{\mathbf{1 2}} / \mathbf{L}\right)\end{array}$ & $\begin{array}{c}\mathbf{H b} \text { conc } \\
(\mathbf{g} / \mathbf{d l})\end{array}$ & $\begin{array}{c}\text { MCV } \\
(\mathbf{F l})\end{array}$ & $\begin{array}{c}\text { MCH } \\
(\mathbf{P g})\end{array}$ & $\begin{array}{c}\text { MCHC } \\
(\mathbf{g} / \mathbf{d l})\end{array}$ & $\begin{array}{c}\text { WBC count } \\
\left(\times \mathbf{1 0}^{\mathbf{9}} / \mathbf{L}\right)\end{array}$ \\
\hline Bovine & $25.59 \pm$ & 12.84 & 9.12 & 41.37 & 13.02 & 34.00 & 12.15 \\
Haemonchosis & 0.03 & \pm 0.01 & \pm 0.01 & \pm 0.03 & \pm 0.01 & \pm 0.001 & \pm 0.02 \\
Apparently & 34.52 & 11.72 & 11.42 & 38.21 & 12.31 & 34.05 & 11.27 \\
Normal Cattle & \pm 0.02 & \pm 0.01 & \pm 0.01 & \pm 0.03 & \pm 0.01 & \pm 0.001 & \pm 0.02 \\
\hline
\end{tabular}

Table 2: Breeds, age and sex of cattle sampled

\begin{tabular}{|c|c|c|c|c|c|c|c|c|}
\hline \multirow[t]{2}{*}{ Breeds } & & \multicolumn{5}{|c|}{ Age } & \multirow[t]{2}{*}{ Bulls } & \multirow[t]{2}{*}{ Cows } \\
\hline & & $\mathbf{P}_{0}$ & $\mathbf{P}_{1}$ & $\mathbf{P}_{2}$ & $\mathbf{P}_{3}$ & $\mathbf{P}_{4}$ & & \\
\hline WF & 175 & 9 & 8 & 30 & 69 & 59 & 85 & 90 \\
\hline SG & 92 & 2 & 11 & 21 & 41 & 17 & 23 & 69 \\
\hline $\mathrm{RB}$ & 37 & - & 3 & 13 & 7 & 14 & 20 & 17 \\
\hline Kuri & 18 & - & 2 & 7 & 7 & 2 & 12 & 6 \\
\hline Total & 322 & 11 & 24 & 71 & 124 & 92 & 140 & 182 \\
\hline
\end{tabular}

Table 3: Breeds, age and sex in cattle with haemonchosis

\begin{tabular}{ccccccccc}
\hline Breeds & Prevalence (\%) & \multicolumn{9}{c}{ Age } & Bulls & Cows \\
\cline { 3 - 7 } & & $\mathbf{P}_{\mathbf{0}}$ & $\mathbf{P}_{\mathbf{1}}$ & $\mathbf{P}_{\mathbf{2}}$ & $\mathbf{P}_{\mathbf{3}}$ & $\mathbf{P}_{\mathbf{4}}$ & $\mathbf{( \% )}$ & $\mathbf{( \% )}$ \\
\hline WF & $72(22.4)$ & 2 & 8 & 17 & 17 & 28 & 25 & 47 \\
SG & $44(13.7)$ & 2 & - & 7 & 31 & 4 & 17 & 27 \\
RB & $12(3.7)$ & - & 3 & 7 & 2 & - & 5 & 7 \\
Kuri & $3(0.9)$ & - & - & - & 3 & - & 2 & 1 \\
Total & $131(40.7)$ & 4 & 11 & 31 & 53 & 32 & $49(15.2)$ & $82(25.5)$ \\
\hline
\end{tabular}

Table 4: Haemonchus infection in cattle based on body condition

\begin{tabular}{cccc}
\hline Body condition & Animals sampled & Number of positive & P-Value \\
\hline Medium (BCS 5-7) & 146 & $88(27.3 \%)$ & $<0.0001$ \\
Good (BCS 8-9) & 176 & $43(13.4 \%)$ & \\
Total & 322 & $131(40.7 \%)$ & \\
\hline
\end{tabular}




\section{Haematologic profile and prevalence survey of haemonchosis}

\section{Discussion}

The highest prevalence of $40.7 \%$ for haemonchosis in this study is in line with the findings of Adedipe et al., (2014) in a previous study in Southwestern Nigeria where a prevalence rate of $41.6 \%$ was reported in this same study area. Our present finding was lower the prevalence of $62.1 \%$ reported by Elele et al., (2013) in South-south Nigeria. Similarly, the current finding reported a lower prevalence compared to the findings of Abebe and Esayas (2001), in the Eastern part of Ethiopia. However, the current finding was higher when compared with the finding of Odeniran et al., (2016) who reported the prevalence of $10.19 \%$ in Ipata abattoir, Ilorin Nigeria. The difference in prevalence rates observed could be due to the sources of the animals, grazing habits, standard of management and changes in seasonal prevalence of haemonchosis (Odoi et al., 2007). The extensive system of managements of these animals prior to slaughter and their feeding habits may also be a factor. This high prevalence may point to developed resistance of the parasites to available anthelminthic drugs in the market. Pasture with high concentrations of animals may also have a high level of contamination with parasite eggs and oocysts, which constitute a risk for infected cattle. The variations in the monthly prevalence may be attributed to changes in the environmental conditions. The two extreme seasonal variations in Nigeria are the wet and dry seasons, the highest prevalence of $40.7 \%$ was recorded during the wet or rainy season while the prevalence reduced with the onset of dry season with no case recorded at the study site in January and February. These findings are consistent with the findings of Jeremiah and Folorunso (2019) on the prevalence of liver flukes in the study area during the two prominent seasons in Nigeria. The zero prevalence in the two months may be attributed to the prevailing hot and dry weather condition at this time of the year. The two components (temperature and moisture) are important ingredients of the microclimate on and in the pasture. A third component, (oxygen) is also important but is rarely a limiting factor except where water-logging occurs. Wet weather creates conditions favorable for parasites to infect animals on pasture (Swai et al., 2006). The level of moisture required is linked to temperature and rainfall. So high temperatures, associated with dry season in Nigeria, inhibit larval development, because evaporation is high. The rainy season began in April and lasted until October (during the year of study) with two peaks in July and September, the first being the higher of the two. Environmental conditions are usually favourable for the development, survival and translocation of pre-parasitic stages of parasitic nematodes during the rainy season. Therefore, there was a gradual buildup of adult worm populations in grazing animals so that peak worm burdens were recorded at about the peak of the rainy season (Swai et al., 2006). Thereafter, worm populations declined with the lowest being encountered about the peak of the dry season. The prevalence and counts of adult Haemonchus placei, followed a similar trend with peak, respectively, occurring about the peak of the rainy season during the study. It has been observed that faecal egg output in cattle is generally low and faecal egg counts are considered to be poor indicator of infection in adult cattle (Gross et al., 1999). However, the number of helminth eggs or larvae in faeces is influenced by several factors such as biotic potential of nematode species, resistance of the host, development stage of the parasite, season of the year, quantity and consistency of the faeces passed out, sensitivity of diagnostic method 


\section{Jeremiah and Banwo}

used. Therefore, the interpretation of faecal egg counts should take into accounts these factors (Gross et al., 1999). Few parasites may produce many eggs and vice versa.

Post-mortem parasite counts provide a more precise assessment of parasite burdens than parasite egg counts (FAO, 2000). Post mortem worm counting permits identification of adult worms and a direct count of worms present in an animal thereby providing a precise assessment of the worm burden (Hansen and Perry 1994). Post mortem worm counting is considered to be the most accurate method of diagnosis of helminthosis, however, it is also expensive. Post-mortem examination is one of the ways to accurately diagnose helminth infection (Soulsby, 1982, Lichtenfels et al., 1994). Haemonchosis was found to be associated with anaemia among the cattle that were found to be positive. The anaemia observed was normochromic and normocytic. Mean PCV, Hb concentration, total $\mathrm{RBC}$ count, $\mathrm{MCV}$ and $\mathrm{MCH}$ were lower in animals positive for bovine haemonchosis compared to those that were negative. The mean total WBC counts were relatively the same in the two groups of cattle. This result agrees with the findings of Gadre et al., (2008) who reported a significant decrease in the haematocrit values of dairy cattle, which were naturally infested with gastrointestinal helminths. Anaemia results from blood loss during worm feeding (Radostits et al., 2006). The last two larval stages, $\left(\mathrm{L}_{3}\right.$ and $\left.\mathrm{L}_{4}\right)$ and the dioecious adults in the abomasum feed on blood from body capillaries and cause haemonchosis (manifested in anaemia, haemorrhagic gastritis, oedema and other complications), often leading to death in severely affected animals (Radostits et al., 2007, Vatta et al., 2001). Low PCV, Hb, RBC counts could therefore, be used to support the diagnosis of haemonchosis, and serve as indices that could be important in monitoring the disease.

Bovine haemonchosis was more prevalent in the White Fulani breed (22.4\%) followed by Sokoto Gudali (13.7\%) breed, there after Red Bororo (3.7\%) breed and the least prevalence was recorded in the Kuri breed $(0.9 \%)$. The order of haemonchosis prevalence recorded among the breeds of cattle agrees with the reports of Adedipe et al., (2014) who reported a breed prevalence of $46.0 \%, 39.1 \%$ and $37.4 \%$ in the White Fulani, Sokoto Gudali and Red Bororo breeds respectively. A predominant cattle breed found across Nigeria was the White Fulani also known as Bunaji (Williamson and Payne 1989). The White Fulani and Sokoto Gudali breeds account for the greater population of cattle in Nigeria although statistics about their proportion in the national herd varies; with $37.2 \%$ and $31.6 \%$ (RIM, 1992), 51\% and $12 \%$ of cattle population, respectively (Lamorde 1998). Variations in prevalence rates associated with cattle breeds may suggest inter-breed difference in regulating immune responses to nematode infection, especially in a situation where all breeds have equal chance of access to contaminated pastures (Waller, 1999). However, this needs further research. In addition, comparative prevalence advantage of the Sokoto Gudali breeds to haemonchosis may partly explain why it is the preferred indigenous breed for beef production. Also, management systems of animals most importantly (helminth control and treatment) could be accountable for the difference in breed prevalence. All age groups of the large domestic ruminants are susceptible to Haemonchus species infection and most researchers have observed higher rate of haemonchosis in the young (Gauly et al., 2006; Kuchai et al., 2011). The prevalence of haemonchosis was higher in adults in the present study, with the highest prevalence for cattle 


\section{Haematologic profile and prevalence survey of haemonchosis}

around three years of age. This finding is consistent with the work of Olaogun and Lasisi (2015) that bovine helminthosis was found most in cattle between 2.5 and 3 years of age. This may be due to increased slaughter of adult cattle compared to the younger ones. In addition, adults might be stressed due to seasonal change and therefore the nematode parasites might have developed resistance against the frequently used anthelminthics, while the young ones might respond to anthelminthic therefore minimizing their infection rate. Analysis of the association of the disease occurrence, using Fisher's exact test has revealed that there was no statistical significant association $(\mathrm{P}>0.05)$ between sex (males $15.2 \%$, females $25.5 \%$ ) and bovine haemonchosis. This finding indicates that sex does not have a statistical influence on the occurrence of haemonchosis. This may be due to equal chance of accessing the oocysts or indifferent protective immunity for the disease. This finding is in agreement with the work of Waruiru et al. (2000), that the sex of the host did not influence the prevalence or intensity of infection with nematode worms. The higher prevalence among the cows in this study, though not statistically significant, agrees with the findings of Emiru et al. (2013) and Vieira et al. (2014) in Ethiopia and Brazil respectively, where female animals were more susceptible to parasite infection than male ones. This was attributed to lowered resistance of female animals due to their reproductive events (i.e. post parturient egg rise) and insufficient/unbalanced diet against higher needs. Higher prevalence observed in cows could be due to the fact that female animals are kept for a longer period on the farm than the males and are often sold for slaughter only when their productivity declines which in part may be due to heavy worm burdens acquired over time. Cattle with "good" and "medium" body condition scores had haemonchosis prevalence of $27.3 \%$ and $13.4 \%$, respectively. The prevalence variation of the parasite in these two groups of cattle with the two types of body conditions was significant $(\mathrm{P}<0.05)$. Similarly, Tewodros and Girja (2012) indicated in Ethiopia that the rate of worm parasite infestation was higher in small ruminants with "medium" body condition compared to those of "good" body condition with prevalence of $81.2 \%$ and $73.6 \%$, respectively. Our finding does not agree with the findings of Radostits et al. (2007) and Odoi et al. (2007) which indicated that animals with poor body condition are highly susceptible to infection and may be clinically affected by worm burdens. Knox et al. (2006) observed that a well-fed animal would not be in trouble with worms, and usually a poor diet can result in more helminth infections. Further clinical research is warranted to unravel the variation in our findings and those of other workers as far as body condition is concerned in relation to bovine haemonchosis. Naturally, haemonchosis would lead to a loss of appetite and poor utilization of food, which will result in a loss of body weight and body condition.

\section{Conclusion}

The study showed that haemonchosis is an important disease of cattle in Ibadan, Nigeria. There is the need for constant monitoring of large domestic ruminants for gastrointestinal parasites, appropriate anthelminthic regimen, and control measures to promote animal production and prevent huge economic losses because of subclinical, acute illness and death in severe burden of parasitism.

\section{Acknowledgements}

The authors thank Prof J. O Adejinmi of the Department of Veterinary Parasitology and 


\section{Jeremiah and Banwo}

Entomology at the University of Ibadan, for his technical assistance during the course of this study. We also sincerely appreciate the abattoir workers at the Bodija Municipal Abattoir slaughter house, Ibadan, Nigeria for their cooperation while carrying out this work.

\section{References}

Abebe, W. and Esayas, G. 2001. Survey of ovine and caprine gastrointestinal helminthosis in eastern part of Ethiopia during the dry season of the year. Revue de Medecine Veterinaire, vol. 152, no. 5, pp. 379-384.

Achi, Y. L., Zinsstag, J., Yao, K., Yeo, N., Dorchies, P. and Jacquiet, P. 2003. Host specificity of Haemonchus spp. for domestic ruminants in the savanna in northern Ivory Coast. Veterinary parasitology, 116(2), 151-158.

Adedipe, O. D., Uwalaka, E. C., Akinseye, V. O., Adediran, O. A. and Cadmus, S. I. B. 2014. Gastrointestinal Helminths in Slaughtered Cattle in Ibadan, South-Western Nigeria. Journal of Veterinary Medicine. ID $923561,6 \mathrm{p}$. http://dx.doi.org/10.1155/2014/9 $\underline{23561}$

Alawa, C. B., Etukudo-Joseph, I. and Alawa, J. N. 2011. A 6-year survey of pathological conditions of slaughtered animals at Zango abattoir in Zaria, Kaduna State, Nigeria. Tropical Animal Health and Production, 43(1), 127-131.

Elele, K., Owhoeli, O. and Gboeloh, L. B. 2013. Prevalence of species of helminthes parasites in cattle slaughtered in selected abattoirs in Port Harcourt, South-south, Nigeria. International Research on Medical Sciences, 1(2): 10-17.

Emiru, B., Amede, Y., Tigre, W., Feyera, T. and Deressa, B. 2013. Epidemiology of gastrointestinal parasites of small ruminants in Gechi district, Southwest Ethiopia. Adv. Biol. Res; 7(5):169-174.

Filani, M. O., Akintola, F. and Ikporukpo, C. O. (Eds.). 1994. Ibadan region. $\mathrm{R}$. Charles Publication in association with Connel Publications.

Food and Agricultural Organisation (FAO). 2000. Distribution and impact of helminth diseases of livestock in developing countries," in FAO Corporate Document RepositoryAgriculture and Consumer Protection.

Gadre, A. S., Maske, D. K., Panchbhai, C. G., Gawande, T. R., Kolte, S. W. and Sirothia, A. R. 2008. Haematological changes in naturally infested dairy animal at central zone of Vidarbha. Veterinary World, Vol.1(2): 47-48

Gauly, M., Schackert, M., Hoffmann, B. and Erhardt, G. 2006. Influence of sex on the resistance of sheep lambs to an experimental Haemonchus contortus infection. DTW. Deutsche tierarztliche Wochenschrift, 113(5), 178-181.

Gibbs, H. C. and Herd, R. P. 1986. Nematodiasis in cattle. Importance, species involved, immunity, and resistance. Veterinary Clin North Am Food Anim Pract 2:211-224.

Gross, S. J., Ryan, W. G. and Ploeger, H. W. 1999. Anthelmintic treatment of adult dairy cows and the effect on milk production. Vet Rec.; 144:581-587. 


\section{Haematologic profile and prevalence survey of haemonchosis}

Hansen, J. and Perry, B., 1994. The Epidemiology, Diagnosis and Control of Helminthes Parasites of Ruminants. A Handbook, ILRAD.

Hoberg, E. P., Kocan, A. A. and Rickard, L. G. 2001. Gastrointestinal strongyles in wild ruminants. Parasitic diseases of wild mammals, 2, 193-227

Jeremiah, O. T. and Banwo G. O. 2018. Interleukins and Acute Phase Proteins of Bovine Sera during Natural Helminth Burden in Ibadan Nigeria. Open Journal of Veterinary Medicine 8, 36-46.

Jeremiah, O. T. and Folorunso, B. T. 2019. Haematologic Profile and Prevalence of Gastrointestinal Nematodes and Liver Flukes in Three Breeds of Slaughtered Cattle in Ibadan Nigeria. Alexandria Journal of Veterinary Sciences, 61 (1), 46-53

Kaufmann, J. 1996. Parasite infection of domestic animals. A diagnostic manual. Birkhause Verlag Basel. Boston, pp. 13-166.

Knox, M. R., Torres-Acosta, J. F. and Aguilar-Caballero, A. J. 2006. Exploiting the effect of dietary suplementation of small ruminants on resilience and resistance against gastrointestinal nematodes. Vet. Parasitol. 139 (4):385-393

Kuchai, J. A., Chishti, M. Z., Manal, M., Ahmad, J., Rasool, M., Dar, S A. and Tak, H. 2011. Prevalence of nematode parasites in Sheep of Ladakh-India. Journal of Agricultural Extension and Rural Development, 3(13), 229-231.

Lamorde, A. G. 1998. Scenario building for the Nigerian Livestock Industry in the 21 st century. In
Proceedings of the Silver Anniversary Conference of the Nigerian Society for Animal Production-Gateway Hotel, Abeokuta, Nigeria. March 21-26.

Landblom, D. G., Paisley, S., Fausti, S., Johnson, P., Gates, R., Salverson, $R$. and Patterson, $H$. H. 2006. Effect of weaning date and retained ownership on cattle performance and forage disappearance in spring-calving beef systems. In ProceedingsAmerican Society of Animal Science Western Section (Vol. 57, p. 139)

Lasisi, O. T., Ojo, N. A. and Otesile, E. B. 2002. Estimation of age of cattle in Nigeria using rostral dentition. Tropical. Vet., 20: 204-208.

Lichtenfels, J. R., Pilitt, P. A. and Hoberg, E. P. 1994. New morphological characters for identifying individual specimens of Haemonchus spp. (Nematoda: Trichostrongyloidea) and a key to species in ruminants of North America. J. Parasitol. 80, 107119.

Odeniran, P. O., Jegede, H. O. and Adewoga, T. O. S. 2016. Prevalence and risk perception of adult stage parasites in slaughtered food animals (cattle, sheep and goat) among local meat personnel in Ipata abattoir, Ilorin, Nigeria. Veterinary Medicine and Animal Sciences; 4(1); 2054-3425

Odoi, A., Gathuma, J. M., Gachuiri, C. K. and Omore, A. 2007. Risk factors of gastrointestinal nematode parasite infections in small ruminants kept in smallholder mixed farms in Kenya. BMC Vet. Res; 3:6.

Olaogun, S. C. and Lasisi, O. T. 2015. 
Bovine Helminthosis: Blood Glucose Levels and Age Influence on Susceptibility in Some Nigerian Breeds of Cattle. Journal of Veterinary Advances, 5(7), 1029-1035.

Place, F. E. 1893. Anaemic diarrhoea in young cattle. The Veterinary Record, 5, 589.

Radostits, O. M., Gay, C. C., Hinchcliff, K. W. and Constable, P. D. 2006. Nematode diseases of the alimentary tract. In Veterinary Medicine, A textbook of the diseases of cattle, horses, sheep, pigs and goats 10th ed. 15411553.

Radostits, O. M., Gay, G. C., Hinchdiff, K. W. and Constable, P. D. 2007. Veterinary Medicine: A textbook of the diseases of cattle, hores, sheep, pigs and goats 10th Ed., Elsevien Health Sciences, Philadelphia, PA,USA. pp. 15411583.

Riggs, N. L. 2001. Experimental crossinfections of Haemonchus placei (Place, 1893) in sheep and cattle. Veterinary parasitology, 94(3), 191-197.

RIM., 1992. Nigerian National Livestock Resource Survey. IV vols. Report by Resource Inventory and Management Limited (RIM) to FDL\&PCS, Abuja, Nigeria.

Rudolphi，C.A. 1803 . Neue Beobachtungen über die Eingeweidewürmer. Archiv Für Zoologie und Zootomie; 3, 1-32.

Saddiqi, H. A., Iqbal, Z., Khan, M. N. and M u h a m m ad, G. 2010 . Comparative resistance of sheep breeds to Haemonchus contortus in a natural pasture infection. Int $J$ Agric Biol, 12: 739-743.

Soulsby E. J. L. 1982. Helminths,
Arthropods and Protozoa of Domesticated Animals. 7th Edition Elbs Bailliere, Tindall and Cassel Ltd. Pp 125-130.

Swai, E. S., Mtui, P. F., Mbise, A. N., Kaaya, E., Sanka, P. and Loomu P. M. 2006. Prevalence of gastro-intestinal parasites infection in Maasai cattle in Ngorongoro district, Tanzania. Livestock Research for Rural Development. Vet. Investig. Centre Tanzania., 18: 1-10.

Tewodros, F. and Girja, L. 2012. Small ruminant haemonchosis: prevalence and associated determinants in randomly selected restaurants and hotels of Gondar Town, Ethiopia. European Journal of Applied Sciences, vol. 4, no. 4, pp. 168-172, 2012.

Travasso, L. P. 1914. Tricostrongylideos brazileiros (III nota previa). Brazil-Med., 28: (34), 325-327

Vatta, A. F., Letty, B. A., van der Linde, M. J., vanWijk, E. F., Hansena, J. W. and Krecek, R. C. 2001. Testing for clinical anaemia caused by Haemonchus spp. in goats farmed under resource-poor conditions in South Africa using an eye color chart developed for sheep. Vet Parasitol, 99: 1-14.

Vieira, V. D., Feitosa, T. F., Vilela, V. L. R., Azevedo, S. S., de Almeida Neto João Leite de Morais, D. F., Ribeiro, A. R. C. and Athayde A. C. R. 2014. Prevalence and risk factors associated with goat gastrointestinal helminthiasis in the Sertão region of Paraíba State, Brazil. Trop. Anim. Health Prod.; 46(2):355-361.

Waruiru, R. M., Kyvsgaard, N. C., 
Haematologic profile and prevalence survey of haemonchosis

Thamsborg, S. M., Nansen, P., Bogh, H. O., Munyua, W. K. and Gathuma, J. M. 2000. The prevalence and intensity of helminth and coccidial infections in dairy cattle in central Kenya. Vet Res Commun; 24(1):39-53

Waller, P. J. 1999. International approaches to the concept of integrated control of nematode parasites of livestock. Int. J. Parasitol. 29: 155-164.
Williamson, G. and Payne, W. J. A. 1989. Introduction to Animal Husbandry in the Tropics. 3rd Edition. Longman group (FE) Hongkong.

Received: $4^{\text {th }}$ February, 2019

Accepted: $29^{\text {th }}$ May, 2019 